\title{
Governance options for science-policy interfaces on biodiversity and ecosystem services: comparing a network versus a platform approach
}

\author{
Christoph Görg ${ }^{1} \cdot$ Heidi Wittmer ${ }^{2}$ - Caitriona Carter ${ }^{4}$. \\ Esther Turnhout ${ }^{5}$ Marie Vandewalle ${ }^{3} \cdot$ Stefan Schindler $^{6,7}$. \\ Barbara Livorell $^{8,9} \cdot$ Alexandra Lux ${ }^{10,11}$
}

Received: 16 February 2016/Revised: 28 April 2016/Accepted: 7 May 2016/

Published online: 30 May 2016

(C) The Author(s) 2016. This article is published with open access at Springerlink.com

\begin{abstract}
Science-policy-interfaces (SPIs) are expected to go beyond the linear model of scientific policy advice through creating spaces for exchange and dialogue between 'policy' and 'knowledge'. Given that most environmental issues require inter- and transdisciplinary approaches, SPIs must take into account a variety of knowledge types, views and interests of scientists, policymakers and other decision makers. Moreover, acceptance and durability of SPIs depend largely on their perceived legitimacy and the credibility of their
\end{abstract}

Communicated by Carsten Neßhöver.

This is part of the special issue on Networking Biodiversity Knowledge.

Christoph Görg

christoph.goerg@aau.at

1 Institute of Social Ecology, University of Klagenfurt, Schottenfeldgasse 29, 1070 Vienna, Austria

2 UFZ Science-Policy Expert Group, Department of Environmental Politics, UFZ - Helmholtz Centre for Environmental Research, Permoserstr.15, 04318 Leipzig, Germany

3 UFZ Science-Policy Expert Group, Department of Conservation Biology, UFZ - Helmholtz Centre for Environmental Research, Permoserstr.15, 04318, Leipzig, Germany

4 Unit: Environment, Territory and Infrastructure, Irstea -Institut National de Recherche en Sciences et Technologies pour l'Environnement et l'Agriculture, 50 Avenue de Verdun-Gazinet, 33612 Cestas Cedex, France

5 Forest and Nature Conservation Policy Group, Wageningen University, Wageningen, The Netherlands

6 Division of Conservation Biology, Vegetation Ecology and Landscape Ecology, Department of Botany and Biodiversity Research, University of Vienna, Rennweg 14, 1030 Vienna, Austria

7 Department of Biodiversity and Nature Conservation, Environment Agency Austria, Spittelauer Lände 5, 1090 Vienna, Austria

8 Centre for Evidence Based Conservation, Bangor University, Bangor, Gwynedd LL57 2DG, UK

9 Present Address: Foundation for Research on Biodiversity (FRB), 195 Rue Saint Jacques, 75005 Paris, France 
knowledge-gathering processes, providing additional challenges for their internal organisation. As the interplay between different knowledge types and decision making is far from neutral, a reflexive approach is required in the design of an SPI so that it is capable of learning from past experiences. The aim of this article is to discuss which governance arrangements could best support the development of an effective and legitimate SPI for European biodiversity politics. We analyse different options for facilitating the implementation of a 'Network of Knowledge' approach. This approach has been developed to improve the interface between diverse knowledge-holder communities and decision making processes for biodiversity and ecosystem services-a field where multi-scalar and multi-dimensional problems arise. In this article, we develop and discuss two stylized extreme governance models as our starting point: an informal network model, which almost entirely depends on the dedication of individuals, versus a more formalized 'platform model, predominantly based on the needs and interests of the organisations involved. We discuss the pros and cons of each of these models in reaching their objectives and in developing sound governing processes for a 'Network of Knowledge'. From this discussion, we derive a recommended design for the reflexive governance of such a network in the context of the European Union and finish by discussing some more general lessons learnt.

Keywords Science-policy-interface $\cdot$ European environmental policy $\cdot$ Research networking $\cdot$ Biodiversity $\cdot$ Ecosystem services

\section{Introduction: governing the interface between science and policy}

The governance of organizations at the interface between science and policy has become a matter of investigation over the last couple of years for several reasons. First, on an international level, new organizations like the Intergovernmental science-policy Platform on Biodiversity and Ecosystem Services (IPBES) have been established, raising questions about their structure and organization (Görg et al. 2010; Turnhout et al. 2012, 2014; Vadrot 2014). Second, existing organizations like the Intergovernmental Panel on Climate Change (IPCC) have attracted increased general scrutiny from both within and outside these bodies due to public concern about "Climate Gate" and debates about the need for a reform of its governance structure (Hajer 2012; Beck et al. 2014). Third, even long-standing sciencepolicy-interfaces (SPIs) such as the International Council of the Exploration of the Sea (ICES) are increasingly rethinking their internal methods and advisory role (Schwach et al. 2007; Wilson 2009).

A broad body of literature suggests that while relevant knowledge is crucial for effective environmental conservation, interactions between knowledge production and knowledge use frequently remain difficult. Over the last couple of years, several conditions or recommendations for effective SPIs have been identified, including ensuring long-term dialogue, mutual learning and institutional support (van den Hove 2007; Young et al. 2013,

10 ISOE - Institute for Social-Ecological Research, Hamburger Allee 45, 60486 Frankfurt/Main, Germany

11 Senckenberg Biodiversity and Climate Research Centre (BiK-F), Senckenberganlage 25, 60325 Frankfurt/Main, Germany 
2014). Other papers have argued that although these recommendations are certainly useful, attempts to establish blueprints for SPIs might fail as there are no 'one-size-fits-all' solutions for complex and varying science-policy issues (Beck 2011; Beck et al. 2014). Indeed, reducing the challenges of designing an appropriate SPI to an instrumental approach for solving environmental problems potentially ignores multiple rationalities, treating scientific knowledge as a neutral input into decision making (Turnhout et al. 2013). As scientific approaches, methods and concepts inevitably contribute to the shaping of problems, and hence can influence decision-making, scientific knowledge is to some degree inevitably political. We therefore need to consider not only the external interplay of science and politics, but also the politics of knowledge within SPIs (Turnhout et al. 2016). What is needed for designing effective and legitimate SPIs is a move away from simplistic notions of 'facilitating dialogue', and 'supporting smooth flows of assumedly neutral knowledge', towards the explicit recognition of the politics of knowledge that are at play, i.e. how knowledge is contested and linked to political struggles. In other words, what is required is a reflexive approach towards SPIs that treats the governance of expertise as a matter of political contestation (Beck et al. 2014). Such a reflexive approach would seek to create internal governance arrangements which are flexible and able to learn from past experiences.

Experiences from existing SPIs suggest that governance arrangements for effective and legitimate SPIs need to be capable of addressing two distinct-yet inter-related-challenges (Carter 2013). First, arrangements need to be developed which can provide for flexible approaches to the collective acquisition and aggregation of science and other knowledge available for the topics concerned. Secondly, arrangements are required which can provide for practically applicable and reflexive mechanisms for communication and exchange between scientists and policy-makers which do not just replicate the 'old' linear supply and demand model. They must be premised instead upon understandings of science and policy as co-constituting each other and as performative practices (i.e. with an emphasis on doing science or policy, not on generic characteristics), as well as remaining open to other knowledge forms (e.g. user knowledge) and policy options (Carter 2013). Accordingly, the governance of SPIs not only seeks to develop structures for the collection and distribution of information, but also to facilitate processes that integrate multiple knowledge forms through networking what might otherwise be distinct and often separated bodies of knowledge.

Against this background, this article draws on work conducted within the KNEU research project ${ }^{1}$ to discuss which governance arrangements could best support an effective and legitimate SPI for the proposed 'Network of Knowledge' (NoK) approach. The NoK was developed to improve the interface between diverse knowledge-holder communities and decision making for European biodiversity politics (see Nesshöver et al. 2016). After first introducing the political and institutional context, we present the methods used. We discuss the potential governance design of a NoK by comparing two extreme stylized models developed as a tool to confront the options and the potential design of such a NoK: an 'informal network model' that depends almost entirely on the dedication of individuals and on flexible structures, versus a 'platform model' with a more formalized organisational structure, responding to the interests of the involved organisations and networks. Next, the pros and cons of these models in achieving their goals for developing sound processes for a

\footnotetext{
${ }^{1}$ KNEU stands for "Developing a Knowledge Network for EUropean expertise on biodiversity and ecosystem services to inform policy making economic sectors" and was an EU FP7 funded project; see Nesshöver et al. (2016).
} 
'Network of Knowledge' are discussed. On the basis of this discussion we develop a recommended design for the governance of a 'Network of Knowledge' for the European context. At the end, we draw conclusions on what can be learned from the developed governance options for the design of SPIs in general.

\section{The 'Network of Knowledge' approach towards science policy interfaces: background and challenges}

There are many different ways of organizing an SPI, depending on objectives, genesis, structures and functions and the political and scientific environment. Moreover, different areas of scientific knowledge and decision making are characterized by specific challenges depending on: the subject matter (e.g. climate change as a global issue vs. biodiversity governance as a more regional/local one); its complexity (e.g. number of scientific disciplines needed); its interlinkages with socioeconomic processes (e.g. socioeconomic relevance of certain topics: are different societal groups affected in different ways? Is nonscientific expertise needed?); the characteristics of the policy field (e.g. level of agreement or conflict) including power relations involved (e.g. Hoppe 2005; Mitchell et al. 2006). Another important factor determining the functioning of SPIs is the way in which they are supported and legitimized by national or international policy processes. Specifically, this means that the design of SPIs has to consider amongst other factors the political mandate of the interface, the degree of independence from decision making and policy processes, the embedding of the interface in existing institutional and regulatory frameworks and its position vis-à-vis other institutions and organizations that may or may not be willing or able to cooperate.

To respond to these challenges, a NoK approach was developed (see Nesshöver et al. 2016 for more details) combining three basic functions: (1) a 'networking approach' to how individual researchers and existing organizations could participate; (2) a 'multiple knowledge basis approach' regarding the kind of expertise involved; and (3) a 'governance approach' capable of interacting with relevant arenas of decision making (e.g. governmental institutions at national and European level). The reasons for that are manifold (see Nesshöver et al. 2016 for more details); concerning the governance structure of such an approach, the proposed building blocks and processes are developed in response to the specific conditions of European policy and European expertise on biodiversity and ecosystem services.

There has already been a long-standing debate on improving the science-policy interface for Biodiversity and Ecosystem Services (BES) at the European level, which has some peculiarities compared with its international counterpart IPBES. The situation in Europe differs from the global level in at least two regards: on one hand, a considerable amount of well-established institutions and organisations working at the science policy interface already exist. Some of them, like the European Environmental Agency (EEA), the Joint Research Centre (JRC) and the International Council of the Exploration of the Sea (ICES, see above), are closely linked, or even directly responsible, to the EU Commission. On the other hand, while the research landscape and the knowledge holder community within Europe is densely populated, it is also more fragmented than within federal states like the USA. Moreover, despite the fact that many policy decisions impacting BES, such as the Common Agricultural Policy or the Common Fishery Policy, are taken at the EU level, most scientific organisations are still related to the national level and part of national 
scientific networks. What is missing, thus, is a coordinated approach, capable of involving a broad variety of scientific networks, learning societies or communities of practice that exist at European or Member State level. Even if some of them have clear linkages towards certain policy arenas, to date there has been no concerted approach to systematically bring these bodies together-both to increase their relevance for policy and decision making and avoid duplication of work.

Moreover, the conditions for establishing a new mechanism in Europe must be considered carefully as the process is driven by some tensions concerning expectations from policy. The origins of such an initiative can be traced back to the European Platform on Biodiversity Research Strategy (EPBRS), which in itself represented a science-policy dialogue on biodiversity research (van den Hove and Sharman 2006; EPBRS 2009). They subsequently found explicit expression in the 2006 'EU biodiversity strategy 2010' which stated that: "The EC (the European Commission; sup. by the authors) will establish an EUmechanism for independent, authoritative research-based advice to inform implementation and further policy development." The seventh European Environmental Action Plan reiterates in more general terms the need "to improve the evidence base for environment policy". Indeed, the policy side has highlighted the need for improvements several times. Directorate-General for Research and Technology Development (DG RTD) in its 7th framework program financed several research projects to analyze and propose processes to improve the SPI on BES (amongst others SPIRAL ${ }^{2}$, and the project informing this article, KNEU) and Directorate-General for the Environment (DG ENV) established a contract to support such a new EU mechanism (Nesshöver et al. 2014). Nevertheless, there is still no mandate from policy or formal initiative to establish a new SPI, let alone a process with strong policy and/or public participation such as an intergovernmental process. Thus it is not easy to identify the needs and options for a European SPI on BES. The basic question, why there is a need for a new SPI and which functions such an organisation might fulfil, therefore remain difficult to answer as there is no clear signal or commitment from policy yet. Thus, after several years of discussions, ambiguities remain about the most feasible options, some of them related to the unclear political context.

Against this background, the research project KNEU explored the needs and options for designing an SPI on BES at the European level. The project developed and tested a proposal to organize the knowledge community in order to make it more responsive to knowledge needs from policy and decision making through creating a NoK, including a structured process for synthesizing knowledge and evidence and informing the research strategy (Livoreil et al. 2016). The major outcome of KNEU was therefore a proposal for a NoK, building on an analysis of existing structures and processes on biodiversity at the European level, including the variety of existing scientific networks, learned societies and communities of practice going beyond the knowledge held by science.

KNEU concluded that networking was central and required to be reflected within any governance arrangement of the proposed new SPI. Network governance is considered to have some advantages compared with other governance modes as it is argued to be more flexible and less bureaucratic (Castells 1996; Keck and Sikkink 1998; Bulkeley 2005; Dedeurwaerdere 2005; Parker 2007). A networking approach may improve the willingness of organisations, networks and individual scientists to participate and to cooperate within the network. Consequently, it was agreed, what is needed is a 'network of networks' approach, connecting existing networks at different levels or scales (from regional or

${ }^{2}$ SPIRAL (science-policy interfaces for biodiversity: research, action, and learning) was an EU FP7 project; see http://www.spiral-project.eu/. 
national up to European and global scale: 'nested network' approach; Görg et al. 2007; Beck 2011). At the same time, however, it was recognised that networks are not always transparent and do not always provide clear lines of responsibilities (Burris et al. 2005; Parker 2007). Knowledge holder organizations need to be committed to working at the interface, a task not necessarily in their mandate and often difficult to achieve (Schindler et al. 2016). Thus, a more structured organizational set up, discussed in the following section as 'a platform approach', can perhaps provide more visibility and establish clear roles, which can make such commitments easier to achieve. To provide credible and legitimate advice, an SPI must thus consider the design, structure and processes of such an approach carefully.

Against this background, appropriate options must be considered over how to best design and implement a NoK approach. This includes not only building upon existing interfaces but also better connecting them with a broad set of knowledge holders, including those beyond scientists.

\section{Methods: consultations and debate on governance options}

To analyse and assess the governance options available for a NoK, we first discussed internally within the KNEU team the challenges involved in creating an SPI mechanism and identified different options and building blocks available for addressing these challenges. For this first step, we built on results from three test cases (on three areas of knowledge: kelp ecosystems, agricultural pest control, and multifunctional floodplain management, see Schindler et al. 2016) as well as on the internal self-evaluation concluded within KNEU at that time (see Carmen et al. 2015). In a second step, we organised a one and a half day expert workshop in January 2014, with participants from KNEU and several SPI experts from different European countries who were not involved in the KNEU project and who had experience on SPIs in the environmental sector. For the method of the workshop, an interactive format was chosen to facilitate an inclusive dialogue on the single governance options and building blocks as well as a critical reflection on the possible governance design for the NoK as a whole. Participants mainly had social science expertise and experience with the set up and functioning of science policy interfaces in different European countries as well as internationally (e.g. IPCC, IPBES). Within this workshop, we also built on comments we had received from the European BES community in past KNEU meetings and other conferences, in particular concerning the feasibility of several options within the existing organizational landscape.

To reduce complexity and to provide a starting point for a critical assessment of governance options, two extreme models were developed at the workshop to group and confront possible alternative options: an 'informal network approach' and a 'platform approach'. In this way, the evaluation was done by contrasting these two models and discussing their respective strengths and weaknesses in light of specific challenges of the European scientific and political context and the overall tasks a NoK should fulfil. In this section, we shortly describe these tasks and the challenges involved before summarising the deliberations on governance options and how different arrangements could be combined. In our presentation, we will focus on the strengths and weaknesses of certain models and design options, but will not elaborate on the discussions emerging at the workshop in more detail, but only on the major outcomes and the final agreement (the recommended model) provided at the end. 
In the development of governance arrangements of SPIs, two different challenges has to be considered (see Introduction above): First, mechanisms for communication and exchange between scientists and policy-makers are required, including how to respond to knowledge needs from decision makers and how to assure credibility and salience of expertise. The governing arrangements therefore need to be flexible for producing jointinitiative advice as well as own-initiative advice, and at the same time capable of responding to any specific requests for knowledge synthesis. Second, new arrangements also needed to be developed which could provide for alternate approaches to the collective acquisition and aggregation of science and scientific advice in order to move beyond a linear model of science policy interaction. This begged the question of which criteria or normative principles should structure the work to ensure the legitimacy of the institution, including new methods for acquiring and aggregating different types of science and knowledge (e.g., how to combine natural and social sciences? How to integrate quantitative and qualitative methods and results to produce integrated and clear advice?).

Additionally, as outlined above, the NoK had to able to fulfil three basic functions (KNEU Team 2014; Nesshöver et al. 2016): a knowledge synthesis function; a research strategy function and a networking and capacity building function.

There are, however, several options available on how to implement these basic functions to create a comprehensive governance design for such a mechanism. The knowledge synthesis function was extensively studied within the project, whereby a prototype procedure was set up (Livoreil et al. 2016) and tested in three trial assessments (Schindler et al. 2016). The design that was chosen envisaged a structured approach, flexible in the choice of appropriate methods with a strong emphasis placed upon specifying the question and choosing appropriate methodologies jointly with the requester and relevant stakeholders to transcend the linear model of scientific policy advice. As these procedures go beyond the compilation and synthesis of relevant knowledge by expert groups (as e.g. IPBES assessments), they require specific expertise and facilitation of the involvement of requesters and stakeholders within the process and thus specific governance procedures. The KNEU team proposed that this role could be undertaken by a so called 'knowledge coordination body' (KCB). In addition, a secretariat would be needed to support the $\mathrm{KCB}$, to link with knowledge holders and to connect the existing networks, thus facilitating the building of a 'network of networks'.

Furthermore, we discussed which kinds of additional governing bodies may serve as building blocks to fulfil and/or support the basic functions of a NoK. These potentially included:

- a body that links to policy (e.g., an SPI forum),

- an internal coordination body or steering committee,

- an advisory board,

- the question of membership (openness vs. commitment of membership organizations).

The building blocks for a NoK were compiled and outlined in a briefing paper for the workshop to discuss and elaborate on challenges and opportunities of different possible governance arrangements. The briefing paper outlined the several objectives that had to be considered simultaneously, some of them very conceptual in nature (see notions on reflexivity, legitimacy and credibility above), some of them more pragmatic (e.g. the level of overlap with existing organisations or institutions or the amount of additional financing needed). Moreover, the missing mandate from policy, and consequently, the ambiguous connection between the NoK and EU policy requests meant that some flexibility had to be built into any design option.

During the discussion at the workshop, participants highlighted that synthesizing knowledge from different disciplines and fields beyond science, and ensuring relevance 
and robustness of the outcomes for policy makers requires time for communication, including for clarifying individual expectations from knowledge providers. This is to ensure that all contributors take ownership of the project and its results to increase the chances of putting results into practice (including impacting policies). Thus, in managing the knowledge synthesis function, governing arrangements were required to manage both interaction between scientists and other knowledge holders, as well as interaction with policy. Issues such as quality assurance and incentives for knowledge holders to become involved needed to be tackled as well (also see Livoreil et al. 2016). The workshop discussions showed that different possible combinations of potential governing bodies, discussed with references to the two extreme models, could create an option space for the recommended governance structure in terms of functional roles and internal decision making. Reflections generated a set of questions around which our discussion was subsequently organized:

- What are the roles of the different bodies involved, what should/could certain NoK bodies decide?

- Who is the final decision maker in case of divergent opinions?

- What will be the role of knowledge/science?

- What should be the role of policy and what should policy decide?

- Who takes decisions on nomination and selection of important bodies (KCB, Assembly, Steering committee, etc.)?

- What are the criteria for nomination and selection of the KCB?

- Who can make early decisions on the governance issue in initial stages of the implementation of the NoK?

In the discussions it also became apparent that the differences among several governance options are gradual and depend on the specific answers to the questions above and the combination of certain building blocks. We therefore decided to outline and compare two stylized extreme models of governance in order to identify potential strengths and weaknesses of different SPI design structures: an 'informal network approach' with minimal level of formalization, where the main initiative would lie with interested individuals that would get together to provide knowledge synthesis within very flexible structures; and a more formalized 'platform model' with a more extended institutional structure, formally involving all relevant actors and a clear division of responsibilities. The two models were developed by subgroups in parallel and then presented and defended in plenary against questions and criticisms of the other subgroup. Strengths and weaknesses as well as open questions outlined below come from these discussions and the comments on the minutes circulated to participants after the workshop. Based on this emergent understanding of strengths and weaknesses, the KNEU team then proposed a hybrid design for initially setting up the NoK. Finally all three models were included in the governance section of the 'white paper' summarizing all results from the KNEU project and proposing a design for a NoK to better articulate current SPIs on BES at the European level (KNEU Team 2014). The white paper was widely circulated and presented at working groups in the European Parliament for feedback.

\section{Translating objectives into governance structures}

The options for addressing the governance challenges of the NoK can be conceptualized as gradients rather than alternate options. Choices need to be made with regard to how the objectives of the NoK can best be achieved by deciding which range of the gradient is 


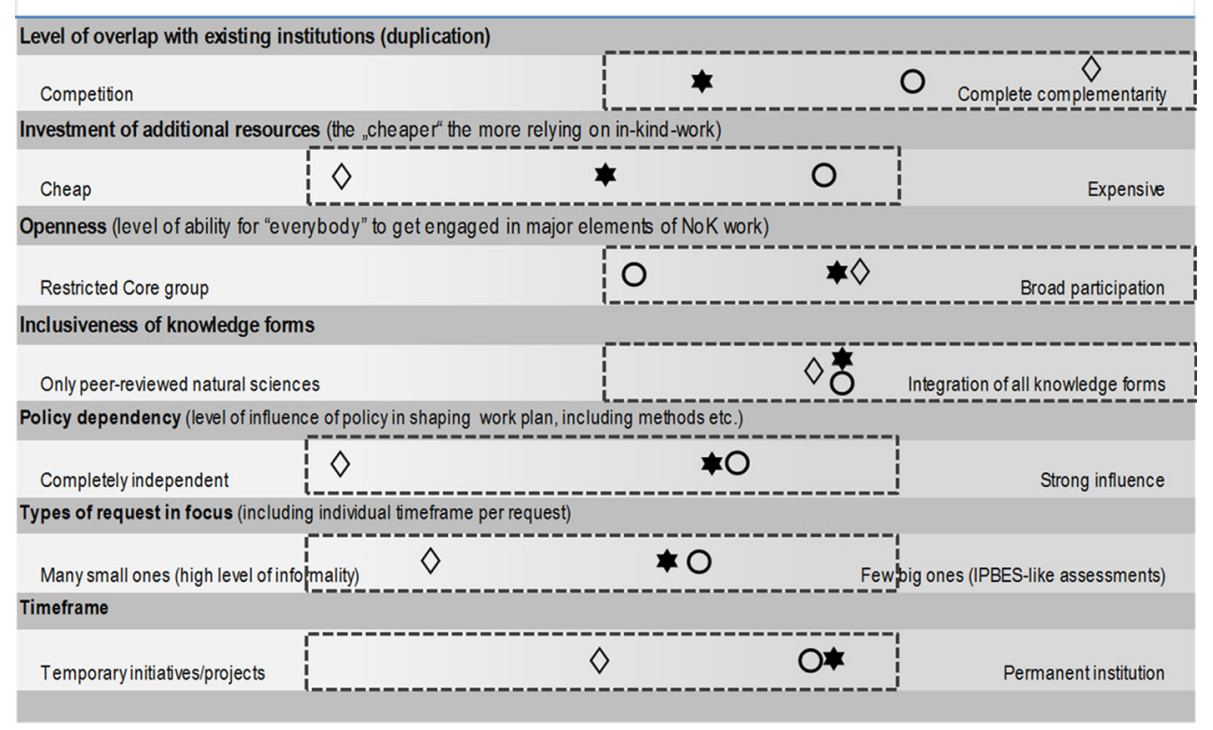

Fig. 1 Criteria to be considered while designing a governance structure; the dash-line boxes indicate realistic range for the NoK based on the objectives and the identified challenge. Approximate positions/ evaluations of the three different models on the different gradients are indicated: Network model (empty diamond), Platform model (empty circle) and recommended model (filled star)

considered desirable (see Fig. 1 below). The first gradient deals with duplication and the level of overlap with existing organizations and networks. It takes into account that there is always a certain level of competition between organizations in the science-policy landscape. The investment of additional resources is the second major gradient. In order to motivate and enable knowledge holders to participate, additional resources would need to be invested, but the level of in-kind-contributions versus additional resources could vary considerably between different models. As in-kind-contributions could also create commitment, a NoK might mainly look for a mix of resources to be invested, i.e., some of the in-kind contribution could come from member organizations, and some resources would come from public money by policy. The balance between the different sources required must be considered carefully, because a high level of public funding might increase dependency on funding bodies. A high degree of openness was considered crucial for the NoK, particularly with regard to the broad range of expertise required and the need for consolidated positions from science. Accordingly, entry barriers to get engaged in NoK activities should be low. Inclusiveness of knowledge forms within the NoK was also judged essential, but would strongly depend on the nature of single requests, as sometimes only a restricted set of very specific knowledge might be needed or valid.

Independence from policy and other vested interests is also crucial, but needs to be balanced with the issues of legitimacy and relevance of the work of the NoK. Consequently, processes to establish a partnership between the NoK and policy, e.g. via the joint scoping of requests, are considered as important. However, a potential membership of policy or other decision makers in the NoK decision bodies would need critical reflection. For the types of requests a NoK might respond to, it is difficult to foresee which area will be most prominent: with many smaller (and short-term) requests, the NoK might improve its relevance, but might also compromise a high quality standard of its outputs and thus 
endanger its credibility. Accordingly, for different kinds of requests, the operational criteria for accepting requests needs to be explicit and possible trade-offs acknowledged.

The timeframe for the setting up a NoK will need to take into account time for constitution and consolidation where a mid-term perspective beyond the usual project-bound timeframe of a few years is crucial. Whether it would need to become a permanent organization remains to be seen.

Figure 1 illustrates the objectives and the extreme ends of the gradients on which the governance of the NoK could be located. While the dash-line boxes indicate a realistic range for the NoK, the different dots locate the extreme models discussed in the workshop (network model and platform model) as well as the conclusions of the KNEU Team for a recommended model.

\section{Informal network model: building on existing capacities and self-organization}

\section{Assumptions used when developing the model}

This model is designed to be light-touch and complementary to existing structures: thus it is also the least expensive. It is expected to be as open as possible and benefit from as many contributions as possible at all levels. More precisely, the assumption is that the network model will be light on bureaucracy and institutionalization, easy to engage with, while avoiding corruption, lobbying, power imbalances or influence of vested interests.

\section{Illustration of the Informal Network Model for the NoK}

This model consists of two permanent bodies:

- A combined $\mathrm{KCB}+$ Secretariat: $\mathrm{KCB}$ members are decentralized, part-time staff seconded in kind and based at their home institutions, and 2-3 permanent full-time positions covering the secretariat function, based in Brussels to create visibility and facilitate interaction with policy. The secretariat's main role would be to provide the entry point to receive requests or suggestions by the members and to organize day to day work.

- A formative external evaluation body, very closely accompanying the process, particularly in the initial years. This body would consist of experts with specific expertise on science-policy interfacing and process management and its main function would be to ensure that procedures are carefully followed and principles not breached. Evaluation is based on criteria that reflect the objectives of the NoK as well as important process qualities. They are applied in means of a formative evaluation that allows for identification of problematic developments early on and to initiate a joint search for solutions to any specific problem encountered. It would provide an external view combined with a full understanding of the background and the challenges involved, it is thus a combination between an evaluation body and an advisory board. In addition another fully external review would be conducted e.g. after 2 and after 5 years of functioning, in order to better understand how the operation is perceived from the outside.

Characteristics of the network model are that membership would be set-up at the individual level, members would self-register, membership fees would be suggested and voluntary, donations being possible, crowd funding would be used to cover requests that do not come from policy, and project money or EC funding would have to cover basic operations. Members would vote on KCB representatives. The model assumes that policy gets organized in a policy coordinating body (PCB), which would be the discussion partner for the $\mathrm{KCB} / \mathrm{sec}$ etariat within the Knowledge synthesis function. 
The KCB could facilitate the setting up of additional working groups for communication, capacity building, or other specific topics of interest to the members. Research strategy development would be treated like any other policy request on a demand basis following the usual procedures envisaged for the knowledge synthesis function.

One suggestion for selecting $\mathrm{KCB}$ members is to let institutions nominate interested individuals by allowing them to contribute some of their time, these would then be elected by members (e.g. requiring a minimum vote) to establish a short list. The formative evaluation body should ensure disciplinary and geographic representation.

\section{Potential strengths}

- The structure and process are light and inexpensive, as mainly based on in-kind contributions;

- Having no institutional membership will bring openness into the whole structure and potentially enable a broader range of disciplines and knowledge forms to be represented;

- External evaluation body: performing formative evaluation by accompanying and back-stopping the process, a combination of evaluation and advisory board;

- High feasibility due to low level of resources and low level of commitment from policy side required.

- Inclusiveness based on voluntary enrolment.

\section{Potential weaknesses}

- KCB could become dominated by certain individuals or groups due to differences in resources, yet without formal accountability mechanisms;

- No formal link with the policy world, and little capacity to be proactive in establishing contacts;

- Voluntary character makes it difficult to manage and to ensure delivery and effectiveness;

- The fact that the research strategy function is not treated separately may imply loss of visibility and independence of this function-which should not "wait" for a request, but should ideally be pro-active in horizon scanning etc.

- Funding: In order to ensure funding in the medium and longer term, the KCB would have to build a strong reputation very quickly. As there is no institutional backing fund raising and reputation building are additional tasks for the KCB to take on.

- The KCB would thus need a "bundle of competencies" - which raises the question of what could realistically be handled by the part-time members of KCB and which skills would be needed in the Secretariat

- Who would be in a position to publicly explain and "defend" the work of the NoK in case results or processes get challenged?

\section{Platform model: institutional commitment and clear allocation of roles}

\section{Assumptions used when developing the model}

This model commits membership organisations to contribute in order to reduce dependence on outside funding and help mobilizing sufficient commitment from the outset. Different bodies would fulfil different roles and could thus divide tasks among them. 


\section{Illustration of the platform model}

Membership at the level of the organizations is the main element constituting the NoK in this model. Organizations becoming members acquire rights but also obligations to contribute. All members form an assembly which selects/elects a steering committee. The steering committee takes all strategic decisions and is supported by a secretariat to do the work and decide on operational issues. The KCB would focus mainly on deciding on which requests the NoK could handle and on organizing the procedures required for the knowledge synthesis-function. The research strategy function would be conducted by a separate body in the NoK, but linked to KCB and the other bodies.

The secretariat will have an important role but having three different bodies with different responsibilities will facilitate clear division of work. Membership by organizations, scientific networks or single projects will help members become active and may help to attract new members. The assembly will ensure members have a sufficient level of information and thus are able to facilitate their engagement as expected. A challenge to solve is that a platform involving membership of large organisations and networks can look like a closed club and well-established members might occupy leading roles over extended periods of time.

An additional evaluation body composed of both internal (formative) evaluation and external reviewers (potentially some from outside Europe) would support the NoK in its operations and identify potential adaptations of processes.

\section{Potential strengths}

- Institutional membership will bring explicit rights, obligations, duties and incentives for the members to invest in the process to make it work. The model thus looks more stable as it has more institutional support, while at the same time providing more visibility to institutions involved;

- The chairperson of the steering committee can "defend" the $\mathrm{NoK} / \mathrm{KCB}$ in case outcomes and/or procedures of KCB's work on organizing the knowledge synthesis function are contested;

- A separate secretariat will have a strong communication role, as well as being a visible entry point and being able to approach the different bodies as needed;

- Regarding the link to the policy process, as a platform it will more likely be seen by EU public bodies as a representative body providing expertise. So it is expected that the Commission will be more likely to produce a statement of support/relevance for the platform and will be more likely to engage in communication with the platform.

\section{Potential weaknesses}

- Membership of strong organisations and networks might weaken the openness in this model, or at least lead to a perception of a closed club with more bureaucratic procedures where individuals are less inclined to join. This could be mitigated by different levels of membership; e.g. associate memberships, individual membership;

- The Platform could be influenced by members' vested interests. Even without influence of vested interests, the platform might still be perceived as influenced both internally or externally. This could be mitigated, however, by having clear rules and structures to limit power games; 
- The platform, with its many bodies might be too formalized and bureaucratic and rely on more heavy structures that would have a high resource need, thus a lot of effort would be needed to keep it running and everyone engaged;

- As the platform is more visible and particularly if it involves governments (in the way of IPBES and IPCC) it might be associated as being part of the Brussels politics and not perceived as independent.

\section{Further questions}

Several other more detailed questions were considered for both models. While detail can make differences for the functionality and effectiveness, these questions do not "tip the balance" for or against one or the other model under consideration:

Data ownership Data ownership might present a challenge: will individuals be able to utilise data belonging to their employer/project when engaging in a knowledge synthesis? Memorandums of Understandings with institutions could bridge the gap with individual members (for example encouraging in-kind contributions), and keeping the institutions on board.

Independence How to safeguard against influence of dominant individuals or groups of individuals? With the combined $\mathrm{KCB} /$ secretariat being the only operating body there is no counterbalancing institution, besides the evaluation body which would reflect on the effectiveness of processes and if principles are adhered to periodically. Limiting the terms for $\mathrm{KCB}$ members e.g. to 3 years (with $\max 2$ consecutive terms) might be able to counteract influence of individuals. Even if there is no interest capture such a model can easily be perceived as a 'closed shop' from the outside.

External evaluation Who would participate in the external evaluation and how would they be chosen? Would this body be based on in-kind contributions (e.g. researchers interested in evaluation of processes)?

\section{Combining the advantages: balancing structural reliability and engagement}

\section{Assumptions used when developing the recommended design}

Both models presented in the previous section have clear strengths and weaknesses. We used these to develop a recommended design that would combine the strengths of both models. It was also important to maintain manageability and keep costs low, while making use of a clear division of tasks. Thus, a main issue when developing the recommended design was to strongly consider what this would mean in practice within the current situation.

The following assumptions were made for shaping the recommended design (see Fig. 1).

- The NoK should be open for active engagement and link up with existing institutions in order to ensure mutual benefits.

- At the same time, it should enable openness and inclusiveness in all its aspects of operations.

- The number and size of internal bodies should be as small as possible, but still ensure efficient work as well as high-quality processes and independent evaluation.

- Independence from vested or political interests is assured by principles and key procedures that are transparent and organized according to scientific standards. 
- With respect to funding and support, the model should allow for in-kind- as well as other types of financial contribution via different pathways.

\section{Governance of the recommended design for the NoK}

The recommended NoK design has four main bodies: A relatively large but decentralized $\mathrm{KCB}$ as part time positions, which meets regularly (3-5 times/year) responsible for the external engagement and strategic development in addressing the three main functions: networking (two dedicated members), research strategy (two dedicated members) and knowledge synthesis function (six dedicated members). Especially for the knowledge synthesis function, the KCB would need more supporting experts, as it will need a mix of expertise on methodologies and processes, as well as a pool of experts to ensure case by case a broad thematic overview and diverse disciplinary backgrounds. For each function, the dedicated members would serve for a term of 3 years (and could be reappointed once) one for each function would take up a leading role. A spokesperson would be elected out of these members. Members of KCB would be in charge of their specific tasks to ensure division of labour and clear responsibilities, but decisions would be taken jointly, e.g. decisions of which requests are tackled in the knowledge synthesis function, and which other activities are taken up based on available resources and overall development

A separate Secretariat, as entry point for all communications, coordinating and supporting the overall work flow processes in the different activities of the three functions jointly with the according experts in the $\mathrm{KCB}$, and conductor of day to day work. The secretariat would consist of a coordinator, two additional scientific process managers, a communications expert, and a part time administrative assistant as a minimum. It should ideally be located in Brussels and host the meetings of the KCB.

An Advisory Board that will allow involvement of a broad set of additional expertise, to follow the work of the NoK and serve as ambassadors of the NoK and provide advice on strategic decisions. It is a light version of the steering committee proposed for the platform model. The Board would consist of high-level experts from all areas of expertise (including policy and society), mainly invited due to the distinct roles they have in their organizations and their experience in the field of environmental and science policy. The chair of the advisory board would be able to publicly explain and defend the work of the KCB in case (correctly followed) procedures are being challenged. At the same time independence is maintained without creating a steering committee with strong possibilities of influencing decisions and developing an own agenda.

The formative Evaluation Body is kept to ensure that procedures and principles are followed and to provide informed outside advice for improving processes of the NoK and ensure joint learning processes and stimulus for improving structures and processes. In the evaluation body should have an ombudsman that gets active in case of challenging situations during the NoK's work. In addition, there should be an external evaluation after 2 and 5 years.

Members of the NoK can be individual experts in the broad fields of biodiversity, ecosystem services and natural resource management, and any field that might prove relevant for the topics tackled in the NoK, including methodologies for synthesis. Experts would be able to register via a simple online procedure and announce their willingness to contribute to the NoK's work in its different functions. They will be able to become engaged in working groups and to elect the potential members of the $\mathrm{KCB}$, once the NoK is properly established. 
Institutions and Networks would get involved via their individual strengths and interests, thus ensuring targeted contributions according to their main areas of expertise, and also committing themselves to support the NoK for the whole community of interest. They will be allowed also to nominate experts for the $\mathrm{KCB}$ according to their interests in the different functions served by the NoK. In the early phase of setting up the NoK, they could actively support other bodies of the NoK, e.g. by supporting the secretariat by in-kind management capacity, but also by helping to identify preliminary actors for the Advisory Board and the Evaluation body.

One strength of this design is that, although there are few internal bodies, a good division of labour is possible and a complementary set of people can speak on behalf of the NoK in different situations and put "faces" to the network. These include the coordinator of the secretariat for receiving requests and easy interaction with policy, the spokesperson of the $\mathrm{KCB}$, particularly on processes and outcomes from the ongoing work on requests, research strategy and building the network. In addition, both the chair of the advisory board, with a focus on strategic dimensions, and an ombudsman, to support a good scientific practice, would be able to provide an informed outside perspective, especially in case of controversies. Co-ordination among them will of course be necessary.

\section{Conclusions}

Governance arrangements of SPIs are crucial to meet the challenges of knowledge politics and to provide a reflexive approach beyond the linear model of policy advice (Beck 2011; Beck et al. 2014; Vadrot 2014; Turnhout et al. 2016). Reflexivity refers to the ability to critically reflect on the knowledge needs in policy and society and to act in a flexible and adaptive way in order to fulfill these needs. This requires the consideration of complex problem structures that are often inherent to BES questions (Görg et al. 2007) and the different bodies of knowledge existing in the field of BES or which might be needed in the context of a specific policy request (Young et al. 2014). In other words, the structures of the SPI should be reflexive in order to be able to be flexible (in response to different types of requests); open (with regard to engagement of different requesters and knowledge holders); discursive (with regard to facilitating mutual learning processes); and self-reflexive (with regard to comparing objectives and functions with outcomes and impacts). Overall, reflexive governance approaches should ensure effectiveness, credibility and legitimacy of a SPI.

As the foregoing discussion shows, no silver bullet exists for the design of such a reflexive SPI. Instead, several normative principles, goals and practical considerations must be balanced in the light of the scientific and political context at hand. The existing institutional landscape of policy institutions and scientific organizations are as important as the policy context and the history of existing networks and the form of their collaboration. This is especially true for the long-lasting debate on improving European biodiversity policy by establishing a new mechanism for scientific advice on BES. Bearing in mind the unclear political situation in terms of a lack of a clear commitment from the policy side for a new SPI for BES issues on the European level, including a lack of mandate and resources, what is called for is a light, self-sustaining structure that builds on and complements existing institutions rather than reinventing the wheel. The initiative is expected to come from science or the broader knowledge community, and this is how the proposal set out in this article was developed. Even for the recommended model, however, some 
open questions remain which ultimately can only be addressed once clear decisions are taken by European policy makers. In the face of an unclear and ambiguous commitment from the policy side, there are limits to our reflections as a research community on how we might wish both to better organize our research on a European-wide scale and better inform policy-making on BES. ${ }^{3}$

Beyond the concrete task to establish a NoK for European biodiversity research and policy, our discussions elaborated here can provide some more general lessons relevant for further discussion on the governance of SPIs in Europe and elsewhere. They emphasize the need to consider different options and the governance structure as a whole carefully. Single building blocks and their role within an overarching structure must be analyzed as the success of an SPI depends to some degree on the governance processes established. Feasibility and practical considerations are important, in particular as a response to the specific political and societal context and the problem structure at hand. At the end, however, the governance structure must be evaluated against the need to ensure reflexivity and institutional learning. Thus, institutional flexibility and the capacity for adaptation to a changing political context must be encouraged to support the credibility and legitimacy of the SPI as much as the transparency of the process and the commitment of single member ship organizations or individuals. If the politics of knowledge requires a reflexive design of a SPI able to reflect the role of experts within decision- and policymaking, then this reflexivity must be encouraged by the governance arrangements. To create a flexible design, to improve reflexivity and stimulate a joint learning processes, the interplay between the $\mathrm{KCB}$, advisory board and evaluation body may be considered as crucial.

However, we should also recognize the limitations of any kind of SPI. At the end of the day, conservation is not (only) about knowledge, or about policy for that matter. What is needed is knowledgeable action and actionable knowledge (Palmer 2012; de Koning et al. 2014; Turnhout et al. 2014). Ultimately it is up to all researchers working across Europe on BES to continue to reflect and exchange on how we might best work together to improve our collective understanding of these multi-dimensional and multi-scalar problems and in so doing, better inform all kind of decision making that affects BES.

Acknowledgments This research was funded by the European Commission under FP7 as coordination action KNEU_- "Developing a Knowledge Network for EUropean expertise on biodiversity and ecosystem services to inform policy making economic sectors" (Grant No. 265299). We are indebted to our colleagues and Carsten Nesshöver for proactive project coordination.

Open Access This article is distributed under the terms of the Creative Commons Attribution 4.0 International License (http://creativecommons.org/licenses/by/4.0/), which permits unrestricted use, distribution, and reproduction in any medium, provided you give appropriate credit to the original author(s) and the source, provide a link to the Creative Commons license, and indicate if changes were made.

\section{References}

Beck S (2011) Moving beyond the linear model of expertise? IPCC and the test of adaptation. Reg Environ Change 11(2):297-306

\footnotetext{
${ }^{3}$ One step that offers options for setting up a Network of Knowledge recently came from research policy in form of a call within H2020 (H2020 SC5-10c-2015) to finance a coordinated support action for "An EU support mechanism for evidence-based policy on biodiversity and ecosystems services." The project EKLIPSE, a co-ordinated support action, has started in February 2016. The proposed governance structure of the project builds on the results from the KNEU project and is similar to the recommended design discussed here, but does not envisage a science policy forum yet. see www.eklipse-mechanism.eu.
} 
Beck S, Borie M, Esguerra A, Chilvers J, Heubach K, Hulme M, Lidskog R, Lövbrand E, Marquard E, Miller C, Nadim T, Nesshöver C, Settele J, Turnhout E, Vasileiadou E, Görg C (2014) Towards a reflexive turn in the governance of global environmental expertise. The cases of the IPCC and the IPBES. GAIA 23/2:80-87. doi:10.14512/gaia.23.2.4

Bulkeley H (2005) Reconfiguring environmental governance: towards a politics of scales and networks. Polit Geogr 24(8):875-902

Burris SC, Drahos P, Shearing C (2005) Nodal governance. Aust J Legal Philos 30:1-43

Carmen E, Nesshöver C, Saarikoski H, Vandewalle M, Watt A, Wittmer H, Young J (2015) Creating a biodiversity science community: experiences from a European Network of Knowledge. Environ Sci Policy 54:497-504

Carter C (2013) Constructing sustainability in EU fisheries: Re-drawing the boundary between science and politics? Environ Sci Policy 30:26-35

Castells M (1996) The rise of the network society. The information age: economy, society and culture. Wiley, Blackwell, Cambridge

de Koning J, Turnhout E, Winkel G, Blondet M, Borras L, Ferranti F, Geitzenauer M, Sotirov M, Jump A (2014) Managing climate change in conservation practice: an exploration of the science management interface in beech forest management. Biodivers Conserv 23:3657-3671

Dedeurwaerdere T (2005) The contribution of network governance to sustainable development. Les séminaires de $1^{\prime}$ Iddri, $\mathrm{n}^{\circ} 13$

EPBRS (2009) Concept note: network of knowledge for biodiversity governance. European Platform for Biodiversity Research Strategy, Brussels

Görg C, Beck S, Berghöfer A, Van den Hove S, Koetz T, Korn H, Leiner S, Nesshöver C, Rauschmayer F, Sharman M, Wittmer H, Zaunberger K (2007) International science-policy interfaces for biodiversity governance-needs, challenges, experiences a contribution to the IMoSEB consultative process. UFZ, Leipzig

Görg C, Nesshöver C, Paulsch A (2010) A new link between biodiversity science and policy. GAIA 3:183-186

Hajer M (2012) A media storm in the world risk society: enacting scientific authority in the IPCC controversy (2009-10). Crit Policy Stud 6(4):452-464

Hoppe R (2005) Rethinking the science-policy nexus: from knowledge utilization and science technology studies to types of boundary arrangements. Poiesis Prax 3:199-215

Keck M, Sikkink K (1998) Activists beyond borders: advocacy networks in international and regional politics. Cornell University Press, Ithaca

KNEU Team (2014) A recommended design for "Biodiversity Knowledge", a network of knowledge to support decision making on biodiversity and ecosystem services in Europe. KNEU Team, Leipzig

Livoreil B, Geijzendorffer IR, Pullin AS, Schindler S, Vandewalle M, Nesshöver C (2016) Biodiversity knowledge synthesis at the European scale: actors and steps. Biodivers Conserv. doi:10.1007/s10531016-1143-5

Mitchell RB, Clark WC, Cash DW, Dickson NM (2006) Global environmental assessments: information, institutions, and influence. MIT Press, Cambridge

Nesshöver C et al. (2016) The Network of Knowledge approach-improving the science and society dialogue on biodiversity and ecosystem services in Europe. Biodivers Conserv. doi:10.1007/s10531016-1127-5

Nesshöver C et al. (2014) Summary report and recommendations on improving the science-policy interface for Biodiversity and Ecosystem Services in Europe (contract: Ref No 07-0307/2013/661961/SER/B2)

Palmer MA (2012) Socioenvironmental sustainability and actionable science. Bioscience 62:5-6

Parker R (2007) Networked governance or just networks? Local governance of the knowledge economy in Limerick (Ireland) and Karlskrona (Sweden). Polit Stud 55(1):113-132

Schindler S et al (2016) The network biodiversity knowledge in practice: insights from three trial assessments. Biodivers Conserv. doi:10.1007/s10531-016-1128-4

Schwach V, Bailly D, Christensen AS, Delaney A, Degnbol P, van Densen W, Holm P, McLay HA, Nielsen K, Martin A, Pastoors S, Reeves A, Wilson D (2007) Policy and knowledge in fisheries management: a policy brief. ICES J Mar Sci 64(4):798-803

Turnhout E, Bloomfield B, Hulme M, Vogel J, Wynne B (2012) Conservation policy: listen to the voices of experience. Nature 488:454-455

Turnhout E, Waterton C, Neves K, Buizer M (2013) Rethinking biodiversity: from goods and services to 'living with'. Conserv Lett 6:154-161

Turnhout E, Neves KDE, Luster E (2014) 'Measurementality' in biodiversity governance: knowledge, transparency, and the intergovernmental science-policy platform on Biodiversity and Ecosystem Services (IPBES). Environ Plan A 46:581-597 
Turnhout E, Dewulf A, Hulme M (2016) What does policy-relevant global environmental knowledge do? The cases of climate and biodiversity. Curr Opin Environ Sustain 18:66-72

Vadrot A (2014) Understanding the establishment of the Intergovernmental Platform for Biodiversity and Ecosystem Services (IPBES): epistemic selectivities in international biodiversity politics, $\mathrm{PhD}$ dissertation at the Institute of Political Science, University of Vienna

van den Hove S (2007) A rationale for science-policy interfaces. Futures 39:807-826. doi:10.1016/j.futures. 2006.12.004

van den Hove S, Sharman M (2006) Interfaces between science and policy for environmental governance: lessons and open questions from the European Platform for Biodiversity Research Strategy. In: Guimaraes Pereira A, Guedes Vaz S, Tognetti S (eds) Interfaces between science and society. Greenleaf, Sheffield

Wilson DC (2009) The paradoxes of transparency: science and the ecosystem approach to fisheries management in Europe. Amsterdam University Press, Amsterdam

Young JC, Watt AD, van den Hove S (2013) Effective interfaces between science, policy and society: the SPIRAL project handbook. http://www.spiral-project.eu/sites/default/files/The-SPIRAL-handbookwebsite.pdf. Accessed Jan 2016

Young JC, Waylen KA, Sarkki S et al (2014) Improving the science-policy dialogue to meet the challenges of biodiversity conservation: having conversations rather than talking at one-another. Biodivers Conserv 23:387-404 